\title{
Initial organ localisation of blood-borne Candida albicans in a rat model of disseminated candidosis
}

\author{
S. KATZ, ${ }^{*}$ J. L. GROSFELD, W. J. FOLKENING, $\dagger$ R. S. ROSENTHAL $\dagger$ and G. J. MERKEL $\ddagger$
}

Department of Surgery, Section of Pediatric Surgery, James Whitcomb Riley Hospital for Children, Indianapolis, $\dagger$ Department of Microbiology and Immunology, Indiana University School of Medicine, Indianapolis, and $\ddagger$ Department of Microbiology and Immunology, Indiana University School of Medicine, Fort Wayne, IN 46805, USA

\begin{abstract}
Summary. The rat was evaluated as an experimental model for disseminated candidosis by quantitating blood clearance and initial organ localisation of ${ }^{3} \mathrm{H}$-leucine-labelled Candida albicans after intravenous injection into the tail or portal vein. Viable or formalin-killed blastoconidia or viable blastoconidia with germ tubes were injected into experimental animals. Blood and tissue samples were obtained up to $24 \mathrm{~h}$ after injection and processed for liquid scintillation counting (to determine the distribution of labelled yeasts) and quantitation of viable organisms. Yeasts were cleared rapidly after intravenous (i.v.) injection by either route, i.e., $<5 \%$ of the radioactivity was detected in the blood after $5 \mathrm{~min}$. The liver and lung were the major organs that sequestered blood-borne yeasts $1 \mathrm{~h}$ after tail vein injection (42.5 SD $15 \%$ and 41.4 SD $6.4 \%$ of labelled yeasts injected, respectively). However, injections via the portal vein resulted in trapping of the yeasts predominantly by the liver. Recovery of radioactivity and viable yeasts from all organs except the kidneys decreased with time. Overall, the results indicated that the rat might serve as a reliable model for short-term studies on organ distribution and thus contribute to our understanding of tissue trophism in candidosis.
\end{abstract}

\section{Introduction}

Normally a harmless commensal of the gastrointestinal tract, oropharynx, skin and female genital tract, Candida albicans may convert to a life-threatening pathogen in predisposed patients. These include neonates, immunosuppressed and post-operative patients and those undergoing prolonged intravenous catheterisation, hyperalimentation and broadspectrum antimicrobial chemotherapy. ${ }^{1-3}$

Potential virulence factors of $C$. albicans, such as morphogenesis and production of extracellular hydrolytic enzymes, continue to be investigated, but there is limited knowledge of the initial fate of bloodborne yeasts, as would be encountered during fungaemia..$^{4-6}$ Blood clearance and organ localisation have been studied in mice, ${ }^{7-9}$ rabbits, ${ }^{10}$ dogs $^{4,5}$ and guinea-pigs, ${ }^{11}$ but the studies were either conducted over an extended period or involved quantitating yeasts in various tissues by radioactive measurements or viable cell counts, but not both methods together. Utilising both would appear beneficial since the

Received 24 May 1991 ; revised version accepted 10 Jan. 1992.

* Present address: Department of Pediatric Surgery, Hadassah University Hospital, PO Box 12000, Jerusalem, Israel 91120.

$\ddagger$ Correspondence should be sent to Dr G. J. Merkel, Department of Microbiology and Immunology, School of Medicine, Indiana University School of Medicine, Fort Wayne Center for Medical Education, 2101 Coliseum Blvd East, Fort Wayne, IN 46805, USA. radioactivity values indicate the total amount of organ trapping whereas the viable cell counts indicate additionally the extent of yeast survival and growth in a particular tissue.

Rats are useful models for studies on mucocutaneous, ${ }^{12-15}$ urinary tract, ${ }^{16,17}$ and gastrointestinal ${ }^{18}$ candidosis, but have seldom been used to investigate blood clearance and organ localisation during fungaemia. Because it would be beneficial to establish one animal model for studies on all phases of candidosis, we evaluated the rat as a model for blood clearance and initial organ localisation of radiolabelled $C$. albicans clinical isolates. We have previously studied the organ localisation of C. albicans in experimentallyinduced obstructive jaundice in rats ${ }^{19}$ and also the in-vitro interaction of $C$. albicans with rat cells in monolayer cultures. ${ }^{20,21}$ This report continues our investigations in vivo and compares the distribution of radiolabelled yeasts to the recovery of viable yeasts after intravenous (i.v.) injection into the tail and portal veins of rats.

\section{Materials and methods}

\section{Experimental animals}

Male Sprague-Dawley rats (Harlen SD Inc., Indianapolis, IN, USA) weighing 175-180 g were housed four/cage and fed standard rodent laboratory chow 
(Purina Mills Inc., St Louis, MO, USA) and tap water ad libitum. Rats were placed in experimental groups according to the route of injection (tail versus portal vein), the clinical isolate of C. albicans employed, and whether the yeasts were viable or formalin-killed blastoconidia, or blastoconidia with germ tubes.

\section{Yeast isolates and culture conditions}

Strains of C. albicans were isolated from clinical specimens derived from different patients and identified by standard techniques. ${ }^{20}$ The strain designations and their origins were as follows: PV-2, tracheal aspirate (bronchopulmonary candidosis); PV-8, suture (wound infection); and PV-25, tongue (oral thrush). Yeast stock cultures were maintained as described previously. ${ }^{20,21}$ Radiolabelled yeasts used in the experiments outlined below were prepared by growing the yeasts for $10 \mathrm{~h}$ (early stationary phase) at $37^{\circ} \mathrm{C}$ on a rotary shaker in Yeast Nitrogen Base (Difco) containing glucose $0.25 \%,\left(\mathrm{NH}_{4}\right)_{2} \mathrm{SO}_{4} 0.5 \%$ and L- $\left(4,5-{ }^{3} \mathrm{H}\right)$ leucine (Amersham, Arlington Heights, IL, USA) $2 \mu \mathrm{Ci} / \mathrm{ml}$. The radiolabelled yeasts were washed twice with $\mathrm{NaCl} 0.9 \%$, cell numbers were determined microscopically with a haemocytometer, and the suspension was adjusted to $1 \times 10^{7}$ blastoconidia $/ \mathrm{ml}$. The final suspensions typically had a specific activity of $1^{3} \mathrm{H} \mathrm{dpm} / 100-1000$ blastoconidia.

Formalin-killed yeasts were prepared by treating radiolabelled blastoconidia, grown as described above, with formalin $10 \%$ in phosphate buffered saline (PBS, $\mathrm{pH} \mathrm{7.2)} \mathrm{for} 15 \mathrm{~min}$ at $5^{\circ} \mathrm{C}$. These yeasts were harvested by centrifugation and washed twice with $\mathrm{NaCl} 0.9 \%$ before injection. Complete killing of the yeasts by this technique was confirmed by inoculating Sabouraud Dextrose Agar (SDA, Difco) with $1 \mathrm{ml}$ of the resulting yeast suspension.

Blastoconidia with germ tubes were prepared after growing the yeasts as described above, washing once with $\mathrm{NaCl} 0.9 \%$, and incubating the yeasts $\left(1 \times 10^{7} / \mathrm{ml}\right)$ at $37^{\circ} \mathrm{C}$ for $1 \mathrm{~h}$ in Dulbecco's modified Eagle medium containing fetal bovine serum $5 \%$ as described previously. ${ }^{21}$ These yeasts were harvested by centrifugation, washed twice with $\mathrm{NaCl} 0.9 \%$ and passed through a 26-gauge needle before injection. These procedures yielded suspensions of individual blastoconidia of which $>90 \%$ had germ tubes 1-2 times the diameter of the parent cell in length. Aggregates were not observed microscopically.

\section{Determination of viable yeasts in organ samples}

Tissue samples $(c .0 \cdot 1 \mathrm{~g}$ each) were weighed and suspended in PBS. After tissue sections had been taken for viability and radioactivity determinations, the entire organs were weighed. The tissue samples were then homogenised in glass dounce homogenisers (Fisher Scientific, Itasca, IL, USA), the resulting tissue homogenates were diluted appropriately with PBS (1 in 10 and 1 in 100$)$ and samples $(0.1 \mathrm{ml})$ were plated on to SDA. The inoculated plates were incubated at $37^{\circ} \mathrm{C}$ for $48 \mathrm{~h}$ before colonies were counted. The results were expressed as the mean colony forming units (cfu)/ intact organ relative to the total number of cfu injected. A specific problem associated with determining the number of viable yeasts by the plate count method is the tendency of $C$. albicans to aggregate. The lack of aggregation in the initial yeast suspensions was confirmed microscopically. However, it was not possible to monitor aggregation which occurred in vivo.

\section{Blood clearance and organ localisation of radiolabelled yeasts}

Experimental animals were sedated with intramuscular injections of ketamine cocktail (Aveco, Ft Dodge, IO, USA), composed of $(/ \mathrm{ml})$ ketamine $100 \mathrm{mg}$, promazine $2.2 \mathrm{mg}$ and atropine $0.4 \mathrm{mg}$; then $1 \mathrm{ml}$ of radiolabelled yeasts $\left(1 \times 10^{7}\right.$ blastoconidia) was injected via a lateral tail vein with a 19-gauge Butterfly infusion set (Abbott Hospitals Inc., North Chicago, IL, USA) or via the portal vein by midlaparotomy. Haemostasis was achieved by direct pressure for $3 \mathrm{~min}$.

To evaluate blood clearance of the radiolabelled yeasts, rats were sedated, the tail was transected, and $50 \mu \mathrm{l}$ of blood was obtained from actively bleeding proximal tail vessels with heparinised micropipettes. These blood samples were processed for scintillation counting as described below.

To evaluate organ localisation of injected radiolabelled yeasts, rats were sedated as before, tissue samples $(0.05-0.10 \mathrm{~g}$ each) were collected at various times up to $24 \mathrm{~h}$ after injection, weighed and placed into scintillation vials. Whole organs were weighed after all samples were collected from a particular animal. Tissue samples for radioactivity measurements were dissolved in $1 \mathrm{ml}$ of Soluene 350 (Packard Camberra Co., Downers Grove, IL, USA) overnight at $50^{\circ} \mathrm{C}$. Isopropanol and $\mathrm{H}_{2} \mathrm{O}_{2} 30 \%$ were then added until the digests clarified. After incubating the samples for $30 \mathrm{~min}, 1 \mathrm{ml}$ of $5 \mathrm{~N} \mathrm{HCl}$ followed by $15 \mathrm{ml}$ of InstaGel X-F scintillation cocktail (Packard) were added. Radioactivity was determined with a 2200 CA Tricarb liquid scintillation analyser (Packard) interfaced with an IBM microcomputer. Data were corrected for quench by use of a calibration curve established by external standardisation for ${ }^{3} \mathrm{H}$. The number of ${ }^{3} \mathrm{H}$ $\mathrm{dpm}$ in individual samples was converted to dpm/ intact organ and the mean dpm/organ was expressed as the percentage of the total $\mathrm{dpm}$ injected. The statistical significance between some of the results was. evaluated by one-way analysis of variance (ANOVA).

\section{Results}

\section{Blood clearance}

Radiolabelled yeasts were cleared rapidly from the 
blood and within $5 \mathrm{~min}$ after injection $c .4 \%$ of the original inocula $(\mathrm{dpm})$ were recovered from blood samples (calculation based on blood volume being $c$. $15 \%$ of total body weight). After incubation for 1 and $2 \mathrm{~h}, c .1 .4 \%$ and $1.7 \%$ of the inocula were recovered, respectively. Blood clearance rates were independent of the yeast isolate used, of culture viability (i.e., untreated or formalin-killed blastoconidia) and of the presence or absence of germ tubes.

\section{Organ localisation of radiolabelled yeasts}

Fig. 1 shows the organ localisation of viable radiolabelled $C$. albicans (PV-8) blastoconidia after tail vein injection. After $1 \mathrm{~h}$, most of the radioactivity was localised in the liver and lungs (42.5 SD $15 \%$ and 41.4 SD $6.1 \%$ of the amount injected, respectively). After $4 \mathrm{~h}$ there was a decrease in the radioactivity recovered from lung tissue but not from liver. A decrease in radioactivity was apparent in both organs after $24 \mathrm{~h}$. The organ localisation and recovery of radioactivity from rats given the PV-2 or PV-25

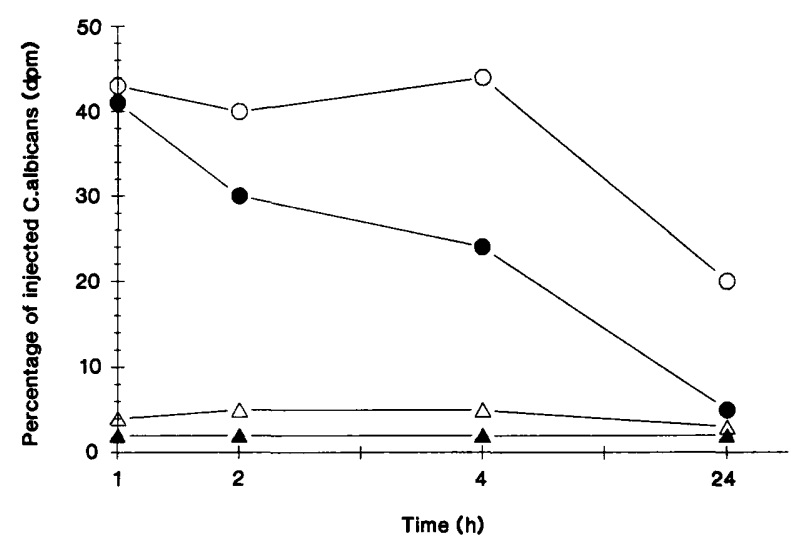

Fig. 1. Organ localisation and recovery of radioactivity after injection of $C$. albicans PV-8 via the tail vein; values are based on the $\mathrm{dpm} /$ organ recovered from the liver $(\mathrm{O}-\mathrm{O})$, lung $(-\longrightarrow)$, spleen $(\triangle-\triangle)$ and kidney $(\boldsymbol{\Lambda}-\boldsymbol{\Delta})$.

Table. Organ localisation after injection of viable and formalin-killed blastoconidia and blastoconidia with germ tubes

\begin{tabular}{|c|c|c|c|c|c|}
\hline \multirow{2}{*}{$\begin{array}{l}\text { Time } \\
\text { (h) }\end{array}$} & \multirow{2}{*}{$\begin{array}{l}\text { Yeast } \\
\text { injected }\end{array}$} & \multicolumn{4}{|c|}{$\begin{array}{c}\text { Mean (SD) percentage } \\
\text { dpm injected/intact organ } \dagger\end{array}$} \\
\hline & & Kidney & Spleen & Liver & Lung \\
\hline 1 & $\begin{array}{l}\text { Viable } \\
\text { Killed } \\
\text { Germinated }\end{array}$ & $\begin{array}{l}1.6(0.4) \\
1.8(0.3) \\
2.5(0.3)\end{array}$ & $\begin{array}{l}3.8(1.0) \\
4.7(0.2) \\
3.0(0.6)\end{array}$ & $\begin{array}{l}42.5(15.0) \\
51.6(12.0) \\
36.3(7.9)\end{array}$ & $\begin{array}{l}41.4(6.4) \\
41.2(11 \cdot 1) \\
53.7(7.1)^{*}\end{array}$ \\
\hline 4 & $\begin{array}{l}\text { Viable } \\
\text { Killed } \\
\text { Germinated }\end{array}$ & $\begin{array}{l}1.5(0.3) \\
1.2(0.3) \\
2.3(0.3)\end{array}$ & $\begin{array}{l}4.3(0.6) \\
3.3(1.0) \\
4 \cdot 2(1.0)\end{array}$ & $\begin{array}{l}44.0(8.0) \\
37.8(8.0) \\
43.4(5.4)\end{array}$ & $\begin{array}{l}23.9(5 \cdot 5) \\
14 \cdot 3(2 \cdot 1)^{*} \\
26 \cdot 9(5 \cdot 4)\end{array}$ \\
\hline 24 & $\begin{array}{l}\text { Viable } \\
\text { Killed } \\
\text { Germinated }\end{array}$ & $\begin{array}{l}1.3(0.2) \\
0.8(0.5) \\
1.2(0.2)\end{array}$ & $\begin{array}{l}2.0(0.6) \\
2.1(0.4) \\
1.8(0.4)\end{array}$ & $\begin{array}{l}20.4(4.2) \\
18.9(4.8) \\
17.9(6.7)\end{array}$ & $\begin{array}{l}3.7(1.3) \\
1.9(0.7) \\
2.3(0.6)\end{array}$ \\
\hline
\end{tabular}

* ANOVA, $\mathrm{p}<0.005$ compared to values obtained with viable blastoconidia.

$\dagger 20$ rats in each test group.

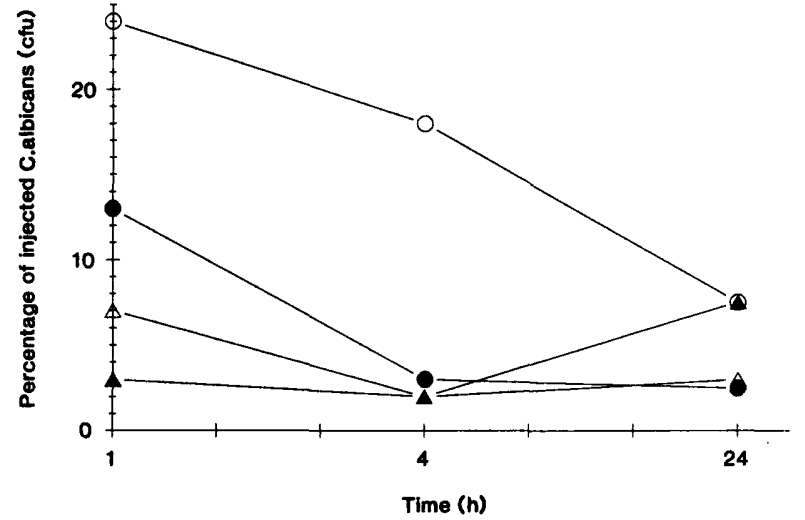

Fig. 2. Organ localisation and recovery of viable $C$. albicans PV-8 after tail vein injection; values are based on the cfu/organ recovered from the liver $\left(\mathrm{O}_{-} \mathrm{O}\right)$, lung $(-\bigcirc)$, spleen $(\triangle \longrightarrow \triangle)$ and kidney $(\mathbf{A}-\mathbf{A})$.

isolates (data not shown) were not significantly different from those reported for the PV-8 isolate.

The organ distributions of radioactivity from rats given PV-8 blastoconidia, formalin-killed blastoconidia and blastoconidia with germ tubes are summarised in the table. Generally, the condition of the injected yeasts had little effect on the recovery and distribution of radioactivity. There was no consistent pattern to the few statistically significant differences evident.

\section{Organ localisation based on viability results}

The distribution and recovery of viable blastoconidia after tail vein injection are shown in fig. 2. In contrast to the recovery of radioactivity, more than twice the number of viable yeasts were recovered from liver samples than from the lungs $1 \mathrm{~h}$ after injection. The recovery of viable yeasts from all organs except the kidneys decreased with time and after $24 \mathrm{~h}$ the concentration of viable yeasts in the kidneys increased to levels similar to those recovered from the liver. The recovery and distribution of viable yeasts were unaffected by the isolate of $C$. albicans injected or whether they were blastoconidia or blastoconidia with germ tubes (data not shown).

\section{Organ localisation after portal vein injection}

The recovery of radioactivity from the lungs and liver after injection of viable blastoconidia (PV-8) via the portal and tail veins are compared in fig. 3. Portal vein injection resulted in the majority of the radioactivity being trapped in the liver. However, after $24 \mathrm{~h}$ similar recovery and organ distribution were observed regardless of the route of injection.

\section{Discussion}

This study, unlike those conducted with other 


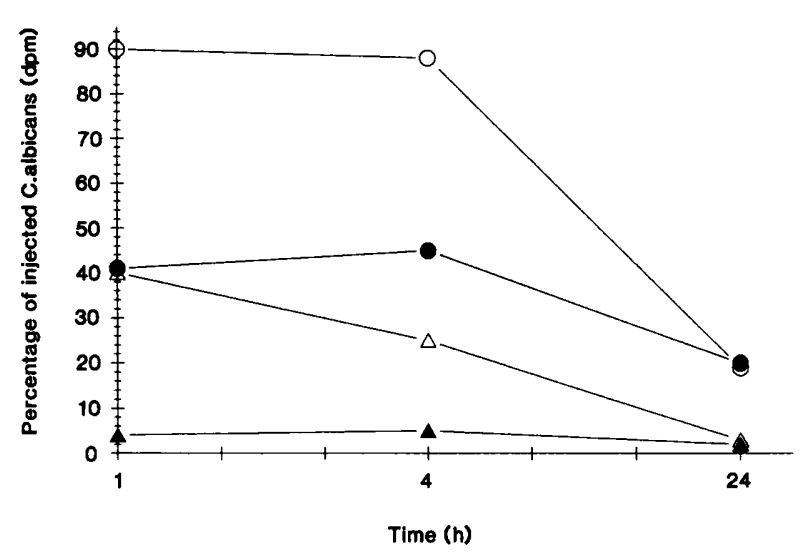

Fig. 3. Comparative recovery of radioactivity from the lungs and livers after injection of $C$. albicans PV-8 via the tail and portal veins; values are based on the dpm/organ recovered from the liver after injection via the portal $(\mathrm{O}-\mathrm{O})$ or tail $(\mathrm{O}-\mathrm{O})$ veins, and from the lung after injection via the portal $(\Delta-\mathbf{\Delta})$ or tail $(\triangle-\triangle)$ veins.

animal models, ${ }^{4-11,22}$ describes blood clearance and initial organ localisation of $C$. albicans by measurements of both radioactivity and viable yeasts recovered from organ samples up to $24 \mathrm{~h}$ after i.v. injection. The work of Stone et al., ${ }^{4,5}$ for example, showed in a qualitative manner the capacity of various tissues to trap circulating $C$. albicans. However, their results demonstrated trapping by the lung only at very high yeast concentrations. Our data, on the other hand, suggest that, in the rat, both lung and liver tissue are quite efficient at sequestering blood-borne yeasts. Although similar amounts of radioactivity were recovered from these organs, the number of viable yeasts in lung tissue was consistently two-fold lower than the number recovered from the liver. The fact that lower amounts of viable yeasts were recovered than predicted from the recovery of radioactivity may have been related to tissue-associated yeast killing or the tendency of $C$. albicans to aggregate, or both." Although aggregation of the yeasts would cause lower than expected numbers of cfu with the plate count technique, we expect that the extent of aggregation would not be greater in lung tissue. Thus, the lung may be more efficient at killing yeasts than the liver, and the presence of live or dead C. albicans in this tissue might stimulate the infiltration of phagocytic cells, ultimately resulting in the formation of micro-abscesses or focal areas of necrosis. ${ }^{1}$ The possibility of this occurring supports the use of both radioactive and viability measurements when examining organ localisation of blood-borne yeasts. Thus, the radioactive determinations estimated the extent or organ trapping of radiolabel (viable, dead, or fragments of yeasts) and the viability determinations indicated the tissue sites where yeast cells may survive or grow. This was particularly true for the kidney where it was shown that relatively small amounts of radiolabelled yeasts were sequestered, but that those trapped were apparently able to grow as shown by the increase in viable yeasts recovered after $24 \mathrm{~h}$.
Evans and Mardon ${ }^{7}$ described organ localisation in pre-leukaemic mice with ATCC strains of $C$. albicans grown at room temperature. In their experimental system they found little difference between the amount of recovered radioactivity and the amount of viable yeasts. Furthermore, they reported that the pseudohyphal form was trapped more by the lung than was the yeast morphology. This is in contrast to our results which demonstrated a nearly identical pattern of fungal distribution after injection of viable blastoconidia, killed blastoconidia and blastoconidia with germ tubes. Our results implied that, in the rat model, organ localisation of blood-borne yeasts was associated with a tissue specificity that was unaffected by the condition of the yeasts. Whereas organ localisation might be related to specific receptors in the tissue for C. albicans, the size of the yeast cell and yeast aggregates may in part explain initial trapping of blood-borne yeasts in capillaries of the lung and liver. Additionally, the increased sequestering of $C$. albicans by the liver following portal vein injection further supports the hypothesis that yeasts entering the blood from the gastrointestinal tract may be readily trapped by the reticulo-endothelial system of the liver. ${ }^{4,6,23}$

The increase in the concentration of yeasts in the kidneys after $24 \mathrm{~h}$ appears to have resulted from growth in vivo. These results are not surprising, as in longer term experimental infections the kidneys are usually the most heavily infected tissue. ${ }^{24}$ Louria $e t$ $a l .{ }^{9}$ were one of the first groups to conduct long term studies on organ localisation of $C$. albicans in mice and they were the first to demonstrate conclusively that the kidney was the only organ to allow growth of the yeast. Their conclusions were based on determining the concentration of viable organisms from various tissues 2-7 days after inoculation. However, shortterm studies combining radioactivity and viability measurements were not conducted.

In conclusion, it appears that the rat may serve as a reliable model for tissue tropism studies with $C$. albicans. Many similarities between our studies and those of others in different species were apparent, but use of two methods for quantitating yeasts indicated that the rate of killing within different organs may be different. The trapping of circulating yeasts by certain organs might result in local or systemic inflammatory reactions or, during immunocompromising conditions, yield focal areas of infection. ${ }^{1}$ Although $C$. albicans produces no recognised exotoxin, secreted acid proteases, ${ }^{25,26}$ phospholipases ${ }^{27}$ or certain cellwall components ${ }^{28,29}$ may contribute to the development of focal lesions in organs that sequester circulating yeasts.

This work was supported in part by a grant from the Indiana University School of Medicine Biomedical Research Committee (GJM), Public Health Service grant RO1-14826 from the N.I.H (RSR) and the Riley Memorial Association 89-2 (JLG). We thank Lucy Clanton, Rosina Cunningham and E. Scott for their excellent technical assistance. 


\section{References}

1. Myerowitz RL, Pazin GJ, Allen CM. Disseminated candidiasis : changes in incidence, underlying diseases, and pathology. Am J Clin Pathol 1977; 68: 29-38.

2. Solomkin JS, Flohr AM, Simmons RL. Indications for therapy for fungemia in postoperative patients. Arch Surg 1982; 117: $1272-1275$.

3. Butler KM, Baker CJ. Candida: an increasingly important pathogen in the nursery. Ped Clin N Am 1988; 35: 543-563.

4. Stone HH, Kolb LD, Currie CA, Geheber CE, Cuzzell JZ. Candida sepsis: pathogenesis and principles of treatment. Ann Surg 1974; 179 : 697-711.

5. Stone HH. Studies in the pathogenesis, diagnosis, and treatment of Candida sepsis in children. J Ped Surg 1974; 9: 127-133.

6. Baine WB, Koenig MG, Goodman JS. Clearance of Candida albicans from the bloodstream of rabbits. Infect Immun $1974 ; 10: 1420-1425$.

7. Evans ZA, Mardon DN. Organ localization in mice challenged with a typical Candida albicans strain and a pseudohyphal variant (39780). Proc Soc Exp Biol Med 1977; 155: 234-238.

8. Trnovec T, Sikl D, Zemanek M et al. The distribution in mice of intravenously administered labelled Candida albicans. Sabouraudia 1978; 16: 299-306.

9. Louria DB, Brayton RG, Finkel G. Studies on the pathogenesis of experimental Candida albicans infections in mice. Sabouraudia 1963; 2: 271-283.

10. Iannini PB, Arai GD, LaForce FM. Vascular clearance of blastospore and pseudomycelial phase Candida albicans. Sabouraudia 1977; 15: 201-205.

11. Gelfand JA, Hurley DL, Fauci AS, Frank MM. Role of complement in host defense against experimental disseminated candidiasis. $J$ Infect Dis 1978 ; 138 : 9-16.

12. Allen CM, Beck FM. Strain-related differences in pathogenicity of Candida albicans for oral mucosa. J Infect Dis 1983; 147: 1036-1040.

13. Howlett JA. The infection of rat tongue mucosa in vitro with five species of Candida. J Med Microbiol 1976; 9: 309-316.

14. Sobel JD, Muller G, Buckley HR. Critical role of germ tube formation in the pathogenesis of candidal vaginitis. Infect Immun $1984 ; 44$ : 576-580.

\section{BOOKS RECEIVED}

\section{Microbial Cell Surface Analysis. Structural and Physicochemical Methods}

Edited by N. Mozes, P. S. HANDLEY, H. J. BusSCHER and P. G. RouXHET. 1991. ISBN 3-527-27987-3. VCH Verlagsgesellschaft mbH. Pp. 368. $£ 58.00$.

This textbook reviews the methods currently available for investigating microbial cell surfaces. Some of the techniques described have been developed only recently and their inclusion reflects the comprehensive nature of the text. The principles and practical aspects, together with the application of the techniques and a useful critique are also described. These will be of particular value to workers in this field.

The first part of the book deals with the current knowledge of the cell wall structure and other related components. The significance of some of the findings is also presented. In the next section, the characterisation of the cell surface by various electronmicroscopy techniques, including freeze etching and drying, freeze substitution, and immunolabelling, is described. Negative staining and carbohydrate detection are also presented in detail. Electronmicrographs
15. Kinsman OS, Collard AE. Hormonal factors in vaginal candidiasis in rats. Infect Immun 1986; 53: 498-504.

16. Tarry WF, Kowalkowski TS, Fisher MA. Renal candidiasis in the rat: effects of ureteral obstruction and diabetes. Urol Res 1989 ; 17 : 367-370.

17. Levison ME, Pitsakis PG. Susceptibility to experimental Candida albicans urinary tract infection in the rat. J Infect Dis 1987 ; 155 : 841-846.

18. DeMaria A, Buckley H, von Lichtenberg F. Gastrointestinal candidiasis in rats treated with antibiotics, cortisone, and azathioprine. Infect Immun 1976; 13: 1761-1770.

19. Katz S, Merkel GJ, Folkening WJ, Rosenthal RS, Grosfeld JL. Impaired clearance and organ localization of Candida albicans in obstructive jaundice. J Ped Surg 1991; 26: 904-907.

20. Merkel GJ, Phelps CL. Factors influencing the interaction of Candida albicans with fibroblast cell cultures. Infect Immun 1988; 56: 792-801.

21. Merkel GJ, Phelps CL. Conditions affecting the amphotericin B mediated inhibition of Candida albicans attachment to cell cultures. Can J Microbiol 1989; 35: 260-264.

22. Sawyer RT. Experimental pulmonary candidiasis. Mycopathologia 1990; 109 : 99-109.

23. Jeunet FS, Meuwissen HJ, Good RA. Fate of Candida albicans in neonatally thymectomized rats. Proc Soc Exp Biol Med $1970 ; 133$ : 53-56.

24. Odds FC. Candida and candidosis, 2 nd edn. London, Baillière Tindall. 1988: 252-278.

25. Ruchel R, Uhlemann K, Böning B. Secretion of acid proteinases by different species of the genus Candida. Zentralbl Bakteriol Mikrobiol Hyg A 1983; 255: 537-548.

26. MacDonald $F$. Secretion of inducible proteinase by pathogenic Candida species. Sabouraudia 1984; 22: 79-82.

27. Barrett-Bee K, Hayes Y, Wilson RG, Ryley JF. A comparison of phospholipase activity, cellular adherence and pathogenicity of yeasts. JGen Microbiol 1985; 131 : 1217-1221.

28. Cutler JE, Friedman L, Milner KC. Biological and chemical characterization of toxic substances from Candida albicans. Infect Immun 1972; 6: 616-627.

29. Blyth W, Stewart GE. Systemic candidiasis in mice treated with prednisolone and amphotericin B. 2. Ultrastructure and evidence for fungal toxin. Mycopathologia 1978; 66: 51-57. are used to illustrate the important structural findings and the value of each of these techniques.

The third part of the book presents methods for determining atomic and molecular composition of the bacterial cell surface. There are also sections on the physical and chemical properties, such as electrical charge, hydrophobicity and surface energy. These areas are notoriously complicated, but the authors have managed to present the information in a concise but lucid fashion. The last section contains studies combining both physical, chemical and structural methods, which are used to investigate the cell surface in relation to adhesion.

The various sections in the book are obviously written by experts in cell wall surface analysis. The text is presented in a logical and well-structured manner and is illustrated with excellent figures and diagrams which augment the comprehensive nature of the text. The book was certainly interesting to read and is, without doubt, one of the best texts available on bacterial cell wall structure and it should therefore have a wide appeal. 